\title{
Ginseng for Reducing the Blood Pressure in Patients with Hypertension: A Systematic Review and Meta-Analysis
}

\author{
Myung-Haeng Hur ${ }^{1}$, Myeong Soo Lee ${ }^{2,3^{*}}$, Hye Jeong Yang ${ }^{4}$, Chan Kim ${ }^{5}$, Ik-Lyul Bae ${ }^{1}$, and \\ Edzard Ernst ${ }^{3}$ \\ ${ }^{1}$ School of Nursing, Eulji University Daejeon 301-746, South Korea \\ ${ }^{2}$ Korea Institute of Oriental Medicine, Daejeon 305-811, Korea \\ ${ }^{3}$ Complementary Medicine, Peninsula Medical School, University of Exeter, Exeter, EX2 4NT, UK \\ ${ }^{4}$ Korea Food Research Institute, Seongnam 463-746, Korea \\ ${ }^{5}$ Department of Physiology and Biophysics, School of Medicine, Eulji University Daejeon 301-746, Korea
}

Ginseng is one of the most-widely used herbal remedies. This systematic review evaluates the current evidence for its use in the reducing blood pressure (BP) in patients with hypertension. Systematic searches of 12 electronic databases were conducted without language restrictions. All randomized clinical trials (RCTs) of ginseng as a treatment for hypertension were candidates for inclusion. Methodological quality was assessed using the Cochrane risk of bias. Five RCTs met the inclusion criteria. The risk of bias was low in most of the trials. Four of the included RCTs compared the effectiveness of ginseng to placebo. The meta-analysis of these data failed to show a statistically significant acute effect on systolic BP (SBP) or diastolic BP (DBP). However, subgroup analyses showed beneficial effects of Korean red ginseng (KRG) on both SBP ( $n=54$, mean difference [MD], $-6.52 ; 95 \%$ confidence interval [CI], -9.99 to $-3.04 ; p=0.0002)$ and DBP ( $n=54, \mathrm{MD},-5.21 ; 95 \% \mathrm{CI},-7.90$ to$2.51 ; p=0.0001)$. Two RCTs tested the long-term effects of ginseng for BP for 24 hours. One of these trials failed to show any benefits of KRG compared to no treatment, and the other failed to show superior effects of North American ginseng compared to placebo. Adverse events with ginseng were none in one trial or not assessed. Collectively, these RCTs provide limited evidence for the acute effectiveness of KRG in the treatment of high BP. The total number of RCTs included in the analysis and the total sample size were insufficient to draw definitive conclusions. More rigorous studies are warranted.

Keywords: Panax, Hypertension, Systematic review, Meta-analysis

\section{INTRODUCTION}

Elevated blood pressure (BP) is a major independent risk factor for cardiovascular disease (CVD) [1]. Complementary and alternative therapies are popular and frequently used by patients with CVD [2]. Survey data indicate that herbal therapies and mind-body therapies are the most commonly used types of complementary therapies [2].
Ginseng is one of the most popular medicinal herbs [3]. Ginseng is claimed to be effective for wide range of conditions, such as cancer [4], erectile dysfunction [5], and postmenopausal symptoms [6]. Cardiovascular effects of ginseng or individual ginsenosides have been studied extensively. Although one study showed that ginseng is likely to be ineffective in lowering BP [7], (c) This is an Open Access article distributed under the terms of the Creative Commons Attribution Non-Commercial License (http://creativecommons.org/licenses/by-nc/3.0/) which permits unrestricted non-commercial use, distribution, and reproduction in any medium, provided the original work is properly cited.
Received 16 Aug. 2010, Revised 28 Sep. 2010, Accepted 20 Oct. 2010

*Corresponding author

E-mail: drmslee@gmail.com

Tel: +82-42-868-9266, Fax: +82-42-861-5800 
other researchers have suggested that ginseng might have potential in lowering high BP [8]. Several in-vivo studies have suggested that ginseng may lower BP in a dose-independent manner [3,9-13].

Considering these findings, it is pertinent to investigate the effectiveness of ginseng in treating hypertension. Currently, no systematic reviews of this subject are available. The objective of this systematic review therefore was to summarize and critically assess the evidence from randomized clinical trials (RCTs) for or against the effectiveness of ginseng as an anti-hypertensive.

\section{METHODS}

\section{Data sources}

The following electronic databases were searched from their inceptions up to May 2010: Medline, CINAHL, EMBASE, PsycInfo, the Cochrane Library 2010 (issue 4), 6 Korean medical databases (Korean Studies Information, DBPIA, Korea Institute of Science and Technology Information, Research Information Center for Health Database, KoreaMed, and National Assembly Library), the Chinese medical database (CNKI), and 3 Japanese electronic databases (Japan Science and Technology Information Aggregator Electronic, Journal@ rchive, and Science Link Japan). The search phrase used was "ginseng AND (blood pressure OR hypertension)".
We also manually searched our departmental files and relevant journals (Focus on Alternative and Complementary Therapies [FACT] and Forschende Komplementärmedizin und Klassische Naturheilkunde [Research in Complementary and Classical Natural Medicine]) up to May 2010. In addition, the references in all selected articles were manually searched for further relevant studies.

\section{Study selection}

All articles that reported a RCT in which human patients with hypertension were treated with any type of ginseng (Panax ginseng, Panax quinquefolius) compared with placebo, active treatments or no-treatment was included. Trials, in which ginseng was used as an adjunct to conventional treatments, were also included if the control group also received the same concomitant treatments as the ginseng group received. Studies comparing two different forms of ginseng and those in which no clinical data were reported were excluded. No language restrictions were imposed.

\section{Data extraction and assessment of risk of bias}

Hard copies of all articles were obtained and read in full by two independent reviewers (MHH and MSL). Data from the articles were validated and extracted according to pre-defined criteria (Table 1). Risk of bias was assessed using the Cochrane classification: random-

Table 1. Summary of randomized controlled clinical trials of ginseng for hypertension

\begin{tabular}{|c|c|c|c|c|c|}
\hline $\begin{array}{l}\text { First author (yr) } \\
\text { Country }\end{array}$ & $\begin{array}{c}\text { No. of patients and } \\
\text { severity of hypertension } \\
\text { age (yr) }\end{array}$ & Treatment (regimens) & BP measurement methods & $\mathrm{BP}$ & Results \\
\hline \multicolumn{6}{|c|}{ Acute effects } \\
\hline $\begin{array}{c}\text { Stavro } \\
(2005)[14] \\
\text { Canada }\end{array}$ & $\begin{array}{l}19 \text { hypertension } \\
\text { (13 drug-treated and } \\
6 \text { drug-naïve) } \\
61 \pm 8 \text { (SD) }\end{array}$ & $\begin{array}{l}\text { (A) NAG (root part, } 3 \text { g, } 6 \text { ses- } \\
\text { sions) } \\
\text { (B) Placebo ( } 3 \text { g cornstarch, } 2 \text { ses- } \\
\text { sions) } \\
\text { Total } 8 \text { sessions, including } 6 \text { NAG } \\
\text { or } 2 \text { placebo with } 7 \text { days washout } \\
\text { between sessions }\end{array}$ & $\begin{array}{l}\text { Ambulatory BP monitor } \\
160 \mathrm{~min} \text { (every } 10 \mathrm{~min} \text { ) }\end{array}$ & $\begin{array}{l}\text { 1) } \mathrm{SBP} \\
\text { 2) } \mathrm{DBP}\end{array}$ & $\begin{array}{l}\text { 1) Average change, } \\
\text { NS; } p<0.05 \text { at } 160 \mathrm{~min} \\
\text { 2) Average change, } \\
\text { NS; } p<0.05 \text { at } 100 \text { and } 140 \mathrm{~min}\end{array}$ \\
\hline $\begin{array}{c}\text { Stavro } \\
(2004)[15] \\
\text { Canada }\end{array}$ & $\begin{array}{l}14 \text { hypertension } \\
\text { (drug-treated) }\end{array}$ & $\begin{array}{l}\text { (A) KRG (body, } 3 \mathrm{~g} / \mathrm{d} \text { ) } \\
\text { (B) KRG (root, } 3 \mathrm{~g} / \mathrm{d} \text { ) } \\
\text { (C) Placebo ( } 3 \mathrm{~g} \text { cornstarch) }\end{array}$ & $\begin{array}{l}\text { Ambulatory BP monitor } \\
160 \mathrm{~min} \text { (every } 10 \mathrm{~min} \text { ) }\end{array}$ & $\begin{array}{l}\text { 1) } \mathrm{SBP} \\
\text { 2) } \mathrm{DBP}\end{array}$ & $\begin{array}{l}\text { 1) } p<0.01 \text { at } 140 \text { and } 160 \mathrm{~min} \text { in } \\
\text { A vs. C; NS in B vs. C } \\
\text { 2) } p<0.03 \text { at } 20,80,130,140,150 \text {, } \\
160 \text { in A vs. C; NS in B vs. C }\end{array}$ \\
\hline $\begin{array}{c}\text { Stavro } \\
(2002)[16] \\
\text { Canada }\end{array}$ & $\begin{array}{l}13 \text { hypertension } \\
\text { (10 drug-treated and } \\
3 \text { drug-naïve) }\end{array}$ & $\begin{array}{l}\text { (A) KRG (0.5 g, } 0.27 \mathrm{mg} \mathrm{Rg} 3) \\
\text { (B) KRG (0.5 g, } 0.81 \mathrm{mg} \mathrm{Rg} 3) \\
\text { (C) KRG (0.5 g, } 2.43 \mathrm{mg} \mathrm{Rg} 3) \\
\text { (D) Placebo (0.5 g, } 0 \mathrm{mg} \mathrm{Rg} 3)\end{array}$ & $\begin{array}{l}\text { Ambulatory BP monitor } \\
20 \text { min before taking capsule } \\
\text { (baseline) and } 180 \text { min (every } \\
15 \text { min) after consumption of } \\
\text { capsule }\end{array}$ & $\begin{array}{l}\text { 1) SBP } \\
\text { 2) DBP }\end{array}$ & $\begin{array}{l}\text { 1) } \mathrm{NS}, \mathrm{A} \text { or } \mathrm{B} \text { or } \mathrm{C} \text { vs. D } \\
\text { 2) } p=0.02 \mathrm{~B} \text { and } \mathrm{D} \text { at } 135 \mathrm{~min} \text { in } \\
\text { favor of } \mathrm{B} \text {; NS for A or C vs. D }\end{array}$ \\
\hline \multicolumn{6}{|c|}{ Long-term effects (longer than 4 wk) } \\
\hline $\begin{array}{c}\text { Stravo } \\
(2000)[17] \\
\text { Korea }\end{array}$ & $\begin{array}{l}17 \text { mild-to-moderate } \\
\text { hypertension }\end{array}$ & $\begin{array}{l}\text { (A) KRG }(4.5 \mathrm{~g} / \mathrm{d} \text { for } 24 \mathrm{mo} \text {, } \\
\text { ranges } 21-27 \mathrm{mo}, n=7) \\
\text { (B) No treatment }\end{array}$ & $\begin{array}{l}\text { Ambulatory BP monitor } \\
24-\mathrm{h}\end{array}$ & 24-h BP & NS (not reported in detail) \\
\hline $\begin{array}{l}\text { Stravo } \\
(2006)[7] \\
\text { Canada }\end{array}$ & 52 hypertensive & $\begin{array}{l}\text { (A) NAG ( } 3 \mathrm{~g} / \mathrm{d} \text { for } 12 \mathrm{wk}) \\
\text { (B) Placebo (3 g cornstarch) }\end{array}$ & $\begin{array}{l}\text { Ambulatory BP monitor } \\
24-\mathrm{h}\end{array}$ & 24-h BP & NS in both SBP and DBP \\
\hline
\end{tabular}

BP, blood pressure; NAG, North American ginseng; DBP, diastolic BP; SBP, systolic BP; KRG, Korean red ginseng; NS, not significant. 
ization, blinding, incomplete outcome measures and allocation concealment. Discrepancies were resolved through discussion between two reviewers (MHH and MSL) and, if needed, by seeking the opinion of a third reviewer (EE). There were no disagreements between the three reviews about the assessment of risk of bias.

\section{Data synthesis}

Mean differences (MD) and 95\% confidence interval (CI) were calculated for systolic and diastolic BP using the Cochrane Collaboration's software (RevMan ver. 5.0; The Nordic Cochrane Centre, Copenhagen, Denmark). When appropriate, we pooled data across studies using random effects models, as long as excessive statistical heterogeneity did not exist. We used the generic inverse variance method in RevMan to analyze the difference in means between the two groups. The chi-square test and the Higgins $I^{2}$ test were used to assess heterogeneity.

\section{RESULTS}

We identified 324 potentially relevant studies, five of which met our inclusion criteria (Fig. 1). The key data are summarized in Table 1 [7,14-17]. Two RCTs [7,14] tested North American ginseng (NAG, Panax quinquefolius), and the other three RCTs [15-17] assessed Korean ginseng or Korean red ginseng (KRG, Panax ginseng). Four of the included trials used a two-armed cross-over double-blind design [7,14-16], while one RCT employed a parallel open design [17]. Three RCTs [14-16] investigated acute effects, and the other two $[7,17]$ assessed long-term effects (lasting greater than 4 weeks) of ginseng on BP. The five trials evaluated a total of 115 patients with hypertension. The doses of ginseng used were $0.27 \mathrm{mg}$ of ginsenosides Rg3 [16], and 3.0 $\mathrm{g}[7,14,15]$ or $4.5 \mathrm{~g}$ [17] of whole ginseng. Three trials measured pre- and post-treatment BP [14-16], while the other two studies used 24-hour BP monitoring $[7,17]$.

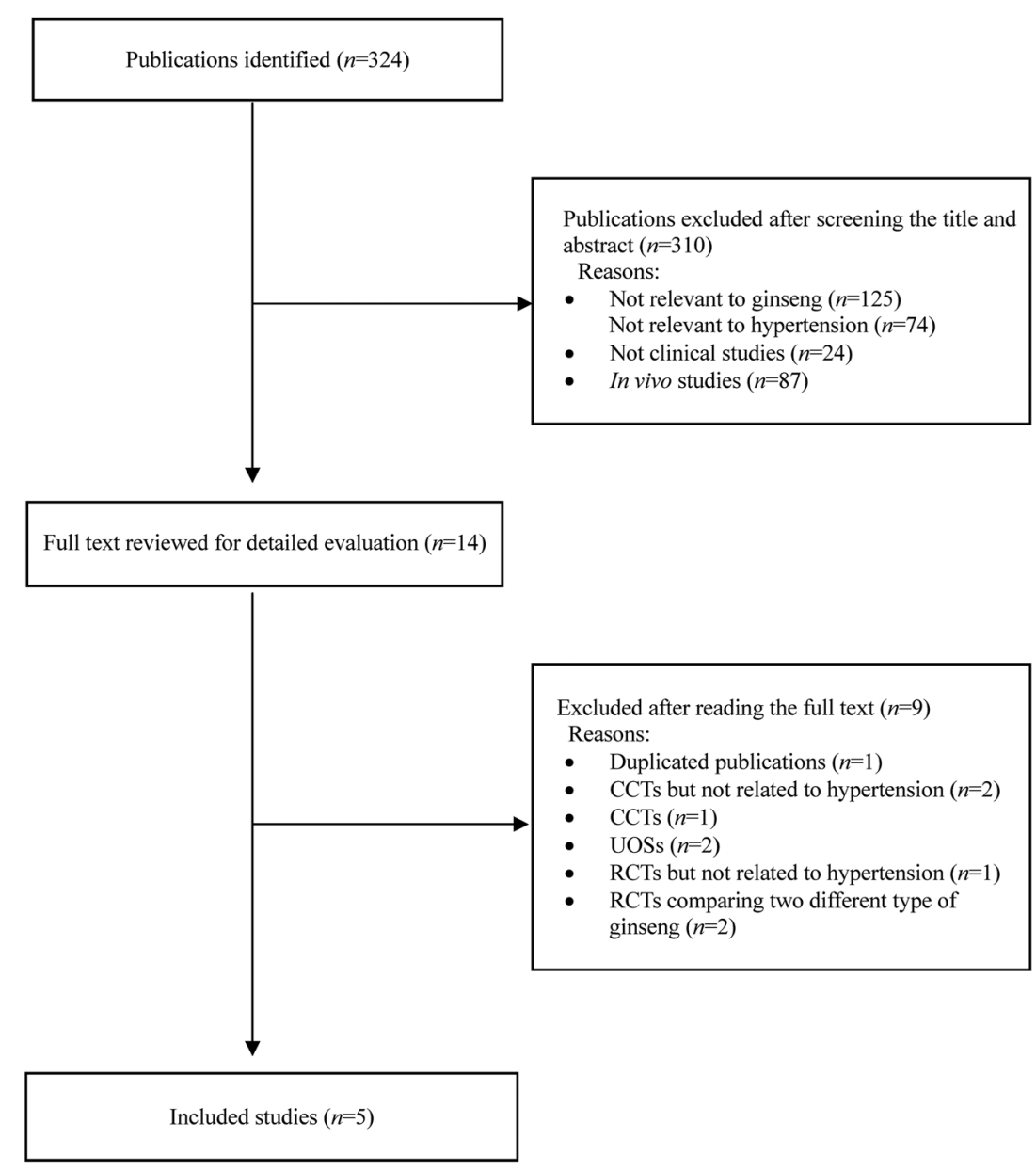

Fig. 1. Flowchart of the trial selection process. CCT, controlled clinical trial; UOS, uncontrolled observational study; RCT, randomized clinical trial. 


\section{Study quality}

Only one described the methods of sequence generation [7], and four described the method of double-blinding [7,14-16]. The risk of bias in incomplete outcome measures was low in all trials. None of the RCTs reported details on allocation concealment.

\section{Outcomes}

\section{Acute effects}

Three RCTs compared the acute effects of ginseng on systolic BP (SBP) and diastolic BP (DBP) to placebo [14-16]. Two RCTs showed a favorable effect of KRG in the treatment of hypertension, lowering both SBP and DBP $[15,16]$, while the others failed to do so with NAG [14]. The meta-analysis of these data [14-16] failed to show that ginseng reduced SBP (Fig. 2A) with high heterogeneity or DBP (Fig. 2B). However, subgroup analysis $[15,16]$ showed an effect of KRG on lowering SBP ( $n=54$, MD, -6.52 ; 95\% CI, -9.99 to $-3.04 ; p=0.0002$; het- erogeneity, $\chi^{2}=0.02, p=0.89, \mathrm{I}^{2}=0 \%$ ) (Fig. $2 \mathrm{~A}$ ) and DBP ( $n=54, \mathrm{MD},-5.21 ; 95 \% \mathrm{CI},-7.90$ to- $2.51 ; p=0.0001$; heterogeneity, $\chi^{2}=0.45, p=0.50, \mathrm{I}^{2}=0 \%$ ) (Fig. 2B).

\section{Long-term effects}

Two RCTs studied the long-term effects of ginseng (KRG or NAG) for $24 \mathrm{BP}[7,17]$. One RCT failed to show a benefit of ginseng compared to no treatment [17], and the other failed to show superior effects of NAG compared to placebo [7].

\section{DISCUSSION}

To the best of our knowledge, this is the first systematic review and meta-analysis of RCTs on the effectiveness of ginseng for the treatment of high BP. Its results suggest that KRG is more effective than placebo in reducing SBP and DBP acutely. However, long-term effects of ginseng on BP were not statistically significant

\section{(A) SBP}

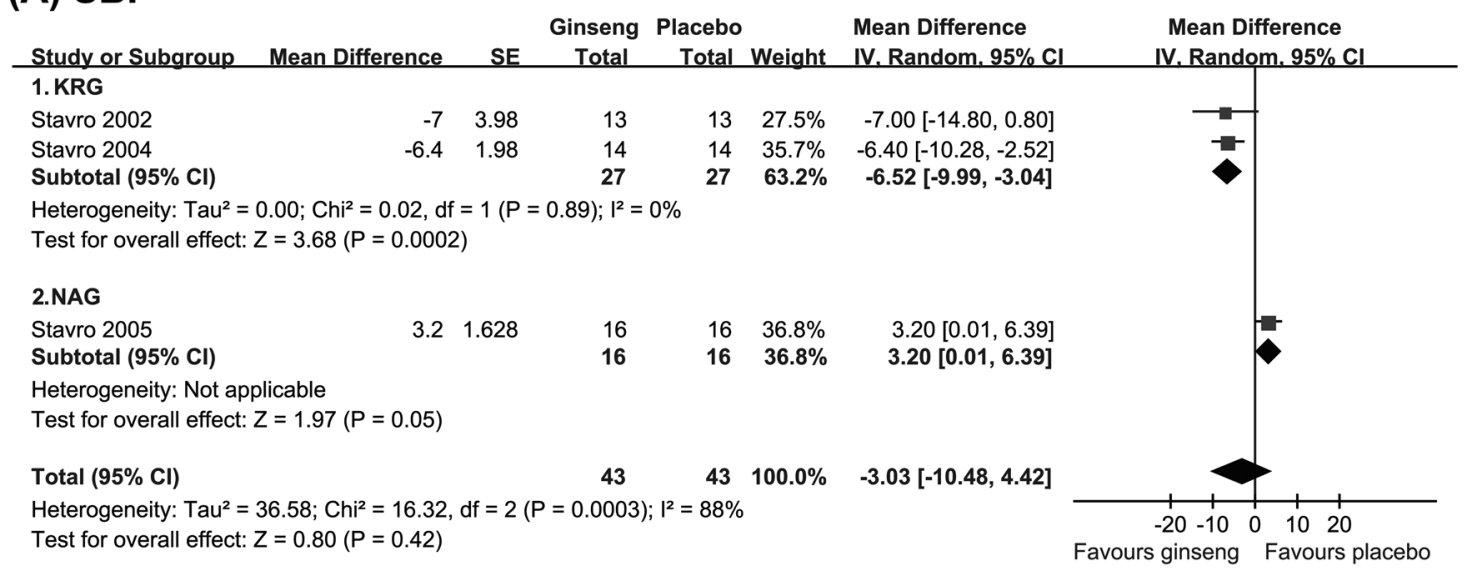

\section{(B) DBP}

\begin{tabular}{|c|c|c|c|c|c|c|c|}
\hline Study or Subgroup & Mean Difference & SE & $\begin{array}{c}\text { Ginseng } \\
\text { Total }\end{array}$ & $\begin{array}{c}\text { Placebo } \\
\text { Total } \\
\end{array}$ & Weight & $\begin{array}{l}\text { Mean Difference } \\
\text { IV. Random, } 95 \% \mathrm{CI}\end{array}$ & $\begin{array}{l}\text { Mean Difference } \\
\text { IV. Random, } 95 \% \mathrm{Cl}\end{array}$ \\
\hline \multicolumn{8}{|l|}{ 1. KRG } \\
\hline Stavro 2002 & -7.3 & 3.41 & 13 & 13 & $25.2 \%$ & $-7.30[-13.98,-0.62]$ & \\
\hline Stavro 2004 & -4.8 & 1.5 & 14 & 14 & $37.0 \%$ & $-4.80[-7.74,-1.86]$ & \\
\hline Subtotal $(95 \% \mathrm{Cl})$ & & & 27 & 27 & $62.2 \%$ & $-5.21[-7.90,-2.51]$ & \\
\hline \multicolumn{8}{|c|}{$\begin{array}{l}\text { Heterogeneity: } \text { Tau }^{2}=0.00 ; \mathrm{Chi}^{2}=0.45, \mathrm{df}=1(\mathrm{P}=0.50) ; \mathrm{I}^{2}=0 \% \\
\text { Test for overall effect: } Z=3.79(P=0.0001)\end{array}$} \\
\hline \multicolumn{8}{|l|}{ 2. NAG } \\
\hline $\begin{array}{l}\text { Stavro } 2005 \\
\text { Subtotal }(95 \% \mathrm{Cl})\end{array}$ & 1.6 & 1.36 & $\begin{array}{l}16 \\
16\end{array}$ & $\begin{array}{l}16 \\
16\end{array}$ & $\begin{array}{l}37.8 \% \\
37.8 \%\end{array}$ & $\begin{array}{r}1.60[-1.07,4.27] \\
1.60[-1.07,4.27]\end{array}$ & \\
\hline \multicolumn{8}{|c|}{$\begin{array}{l}\text { Heterogeneity: Not applicable } \\
\text { Test for overall effect: } Z=1.18(P=0.24)\end{array}$} \\
\hline Total $(95 \% \mathrm{Cl})$ & & & 43 & 43 & $100.0 \%$ & $-3.01[-8.36,2.33]$ & \\
\hline \multicolumn{7}{|c|}{$\begin{array}{l}\text { Heterogeneity: } \text { Tau }^{2}=17.88 ; \mathrm{Chi}^{2}=12.85, \mathrm{df}=2(P=0.002) ; I^{2}=84 \% \\
\text { Test for overall effect: } Z=1.10(P=0.27)\end{array}$} & 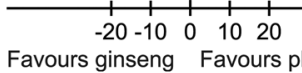 \\
\hline
\end{tabular}

Fig. 2. Forest plot of acute effects of ginseng on (A) systolic blood pressure (SBP) and (B) diastolic blood pressure (DBP) in patients with hypertension. KRG, Korean red ginseng; NAG, North American ginseng, $\mathrm{Cl}$, confidence interval. 
when compared to no treatment or placebo. The number of trials, the total sample size and the methodological quality of the primary studies were low.

A standard scoring system was used to quantify the probable bias inherent in the studies based on the description of randomization, blinding and withdrawals. Of the five RCTs, four [7,14-16] reported the details of their double-blinding procedures. Four RCTs were of good methodological quality with Jadad scores of four [14-16] or five [7]. The remainder only received a score of two [17]. None of the RCTs reported the concealment of treatment allocation. Trials with inadequate blinding or allocation concealment may lead to selection bias and are likely to show exaggerated treatment effects [18]. Two RCTs were published only as abstracts, so they had not been formally peer reviewed and lacked essential details. Thus, the reliability of the evidence presented here is clearly limited.

Although 4 of the 5 RCTs studied used a placebo as a control, none reported successful blinding. Three RCTs used starch with ginseng flavor as a placebo, but the other trials did not report details about their placebos $[7,14,15]$. Unblinding may have occurred, thereby increasing the possibility of an overestimated treatment effect [18]. To reliably account for a placebo effect, it is crucial that the placebo intervention be indistinguishable from the real treatment. Therefore, the success of attempts to blind the study should be assessed, reported and accounted for when interpreting the data. None of the studies reported a power calculation, and sample sizes were very small in most of the included RCTs. Therefore, the results are also prone to a type II error.

The magnitude of ginseng's effect on SBP and DBP varied according to the origin of the ginseng. This result may be due to differences in the active compounds because the origin and the processing of ginseng are important. However, the extent to which red ginseng's therapeutic effects are dependent on the availability and composition of the preparation is unclear. The optimum dose of red ginseng is also unknown. Three of the trials used a treatment of $3.0 \mathrm{~g}$ of ginseng daily $[7,14,16]$, while one trial [17] used $4.5 \mathrm{~g}$ and one used [15] a range of doses from $0.27 \mathrm{mg}$ to $2.43 \mathrm{mg}$ of $\mathrm{Rg}_{3}$. A clinical trial comparing dose dependency has not yet been performed.

The reported reductions in SBP and DBP attributed to KRG were 6.52 and $5.21 \mathrm{mmHg}$, respectively. Relative to the BP reductions achievable with conventional anti-hypertensive drugs, these effect sizes seem small. Prior research has established that a BP reduction of 12 $\mathrm{mmHg}$ to $13 \mathrm{mmHg}$ can reduce heart attacks by $21 \%$, strokes by $37 \%$, and all deaths from CVD by $25 \%$ [19]. Considering that the estimated direct and indirect costs of high BP totaled about $\$ 73.4$ billion in 2009 [19], further research in this area would also be beneficial on an economic level.

Possible mechanisms of BP reduction by red ginseng may be mediated by nitric oxide (NO) production. Ginsenosides have been shown to stimulate NO production in aortic endothelial cells, providing a vasoprotective effect [10-13,20]. In addition to vasodilatation, endothelial-derived NO has anti-atherosclerotic properties [20]. More basic research is needed to fully understand the mechanisms of action of red ginseng.

Adverse events with red ginseng were none [14] or not assessed [7,15-17]. Currently, no post-marketing surveillance studies for red ginseng exist. A review of the safety profile of red ginseng revealed no evidence of adverse drug reactions in humans taking normal doses, but it also points out the lack of data on long-term use.

Our review has a number of significant limitations. Although much effort was made to retrieve all RCTs relevant to our study, we cannot be absolutely certain that our searches identified all relevant trials. Moreover, selective publishing and reporting are major sources of bias and should be taken into consideration [21,22]. It is conceivable that several negative RCTs exist but remain unpublished, which may distort the overall picture. It is noteworthy that a number of studies were funded by manufacturers or associations of ginseng products, which may have introduced a degree of bias. Most of the trials sponsored by the ginseng industry revealed a positive outcome. In this review, three of them were supported by a company associated with red ginseng (KT\&G Corp., Daejeon, Korea) or NAG (Ontario Ginseng Growers Association, Ontario, Canada), causing concern over one possible bias in this systematic review. Another possible bias derives from the lack of diversity in the sources of data; four of the included trials were conducted by one group of researchers, which may represent a lack of reproducibility. Further limitations include the paucity of data and its often suboptimal methodological quality. Some of the RCTs included in the present review were not successful in minimizing bias. These facts limit the conclusiveness of this systematic review.

Collectively, these RCTs provide limited evidence for the acute effectiveness of red ginseng in the treatment of hypertension. No long-term benefits were noted. The total number of RCTs included in the analysis and the total sample size of the primary studies were insufficient 
to draw definitive conclusions. Further, more rigorous trials are warranted.

\section{ACKNOWLEDGEMENTS}

Myung-Haeng Hur and Chan Kim were supported by Mid-career Researcher Program through NRF grant funded by the MEST (No. 2009-0083800).

\section{REFERENCES}

1. World Health Organization. WHO CVD-risk management package for low- and medium-resource settings. Availble from: http://whqlibdoc.who.int/publications/2002/9241545852. pdf.

2. Yeh GY, Davis RB, Phillips RS. Use of complementary therapies in patients with cardiovascular disease. Am J Cardiol 2006;98:673-680.

3. Nam KY. Clinical applications and efficacy of Korean ginseng (Panax ginseng C.A. Meyer). J Ginseng Res 2002;26:111131.

4. Helms S. Cancer prevention and therapeutics: Panax ginseng. Altern Med Rev 2004;9:259-274.

5. Jang DJ, Lee MS, Shin BC, Lee YC, Ernst E. Red ginseng for treating erectile dysfunction: a systematic review. Br J Clin Pharmacol 2008;66:444-450.

6. Shim MK, Lee YJ. Ginseng as a complementary and alternative medicine for postmenopausal symptoms. J Ginseng Res 2009;33:89-92.

7. Stavro PM, Woo M, Leiter LA, Heim TF, Sievenpiper JL, Vuksan V. Long-term intake of North American ginseng has no effect on 24-hour blood pressure and renal function. Hypertension 2006;47:791-796.

8. Han KH, Choe SC, Kim HS, Sohn DW, Nam KY, Oh BH, Lee MM, Park YB, Choi YS, Seo JD et al. Effect of red ginseng on blood pressure in patients with essential hypertension and white coat hypertension. Am J Chin Med 1998;26:199-209.

9. Kim ND, Kang SY, Schini VB. Ginsenosides evoke endothelium-dependent vascular relaxation in rat aorta. Gen Pharmacol 1994;25:1071-1077.

10. Toda N, Ayajiki K, Fujioka H, Okamura T. Ginsenoside potentiates NO-mediated neurogenic vasodilatation of monkey cerebral arteries. J Ethnopharmacol 2001;76:109113.

11. Jeon BH, Kim CS, Kim HS, Park JB, Nam KY, Chang SJ.
Effect of Korean red ginseng on blood pressure and nitric oxide production. Acta Pharmacol Sin 2000;21:10951100.

12. Jeon BH, Kim CS, Park KS, Lee JW, Park JB, Kim KJ, Kim SH, Chang SJ, Nam KY. Effect of Korea red ginseng on the blood pressure in conscious hypertensive rats. Gen Pharmacol 2000;35:135-141.

13. Akasaka Y, Takahashi E, Miyate Y, Kudo K, Ikeda M, Shimizu C, Tachikawa E, Kashimoto T. Effect of red ginseng on blood pressure, heart rate and sympathetic activity in 5-hydroxydopamine treated rats. Eur J Pharmacol 1990;183:1004.

14. Stavro PM, Woo M, Heim TF, Leiter LA, Vuksan V. North American ginseng exerts a neutral effect on blood pressure in individuals with hypertension. Hypertension 2005;46:406-411.

15. Stavro PM, Woo M, Vuksan V. Korean red ginseng lowers blood pressure in individuals with hypertension. Am J Hypertens 2004;17(Suppl 1):S33.

16. Stavro PM, Hana AK, Vuksan V. The effect of Korean red ginseng extracts with escalating levels of ginsenoside Rg3 on blood pressure in individuals with high normal blood pressure or hypertension. Am J Hypertens 2002;15(Suppl 1):A34.

17. Sung J, Han KH, Zo JH, Park HJ, Kim CH, Oh BH. Effects of red ginseng upon vascular endothelial function in patients with essential hypertension. Am J Chin Med 2000;28:205-216.

18. Schulz KF, Chalmers I, Hayes RJ, Altman DG. Empirical evidence of bias. Dimensions of methodological quality associated with estimates of treatment effects in controlled trials. JAMA 1995;273:408-412.

19. Center for Disease Control and Prevention. Heart disease and stroke prevention. Addressing the nation's leading killers: at a glance 2009. Availble from: http://www.cdc.gov/ chronicdisease/resources/publications/AAG/pdf/dhdsp.pdf.

20. Yu J, Eto M, Akishita M, Kaneko A, Ouchi Y, Okabe T. Signaling pathway of nitric oxide production induced by ginsenoside Rb1 in human aortic endothelial cells: a possible involvement of androgen receptor. Biochem Biophys Res Commun 2007;353:764-769.

21. Ernst E, Pittler MH. Alternative therapy bias. Nature 1997;385:480.

22. Pittler MH, Abbot NC, Harkness EF, Ernst E. Location bias in controlled clinical trials of complementary/alternative therapies. J Clin Epidemiol 2000;53:485-489. 